Maya Archaeology and Ethnohistory 
The Texas Pan American Series 


\section{Maya Archaeology and Ethnohistory}

Edited by Norman Hammond and Gordon R. Willey

$\checkmark$ University of Texas Press Austin 
The Texas Pan American Series is published with the assistance of a revolving publication fund established by the Pan American Sulphur Company.

Library of Congress Cataloging in Publication Data

Cambridge Symposium on Recent Research in Mesoamerican Archaeology, 2d, 1976.

(The Texas Pan American series)

Papers presented at the Second Cambridge Symposium on Recent Research in Mesoamerican Archaeology, Aug. 29-31, 1976, which was held under the auspices of the Centre of Latin American Studies, Cambridge University.

1. Mayas-Congresses. 2. Mayas-Antiquities-Congresses. 3. Mexico-Antiquities-Congresses. 4. Central America-AntiquitiesCongresses. I. Hammond, Norman. II. Willey, Gordon Randolph, 1913- III. Cambridge. University. Centre of Latin American Studies. IV. Title.

F1435.C3 $1976 \quad 972 \quad 78-19088$

ISBN 0-292-75040-4

Copyright $\mathbb{C} 1979$ by the University of Texas Press

All rights reserved

Printed in the United States of America

Grateful acknowledgment is made to the College of Fine Arts, University of New Mexico, for permission to reprint material previously published in New Mexico Studies in the Fine Arts, copyright The Regents of the University of New Mexico.

ISBN 978-0-292-76256-5 (library e-book)

ISBN 978-0-292-76257-2 (individual e-book) 